\title{
LA NECESIDAD DE LEGISLACIÓN SOBRE LOS HIDRATOS DE GAS EN CHILE*
}

\section{EDUARDO ROIG MONGE**}

RESUMEN: Los hidratos de gas son materia de discusión Química y Política. Estos últimos expertos ven una oportunidad económica de relevancia, intentando satisfacer las necesidades energéticas contemporáneas en Chile, debido a su descubrimiento dentro de jurisdicción. Mirando la falta de unanimidad en la interpretación que debe darse al bien, su exploración y explotación, este trabajo intenta explicar la naturaleza no concesible de esta manifestación de, al parecer, bastante importancia socioeconómica y entregar finalmente un avance al exégeta jurídico, principalmente mediante un análisis en ese carácter, mostrando finalmente la necesidad y obligación del Estado chileno de legislar y su respectivo contenido mínimo.

PALABRAS CLAVE: Hidratos de gas - dentro de jurisdicción - Metano - explotación - exploración

\section{THE NEED OF GAS HYDRATE LEGISLATION IN CHILE}

ABSTRACT: Gas hydrates are subject of Chemical and Political discussion. The experts on the subject see this as an important economic opportunity, trying to meet the contemporary energy needs in Chile because of its discovery within jurisdiction. Looking at the lack of unanimity in the interpretation that should be given to the good, its exploration and exploitation, this paper will attempt to explain the nature of this event, of apparently, considerable socioeconomic importance and, conclusively give deliver an advance to the legal exegete, mainly through an analysis in that matter, finally showing the need and obligation of the Chilean state to legislate within a certain minimal content.

KEY WORDS: Gas hydrates - within jurisdiction - Methane - exploitation - exploration

Fecha de recepción: 11 de abril de 2013.

Fecha de aceptación: 14 de abril de 2014.

** Abogado. Licenciado en Ciencias Jurídicas, Universidad Bernardo O’Higgins. Correo electrónico: ejrmonge@gmail.com. 
Sumario: Introducción. 1. Aspecto bioquímico. 1.1. Concepto y advances. 1.2. Importancia económica, medio ambiente y seguridad. 2. Aspecto exegético 2.1. El gas: inaplicabilidad del estatuto minero concesional 2.2. El agua: alejándose del código y la concesión 2.3. Expresión del bien común y función social 2.4. Una naturaleza jurídica 2.5. Obligaciones estatales 2.5.1. La protección medioambiental 2.5.2. Obligaciones sobre derechos humanos, comerciales y la seguridad. 3. Alguna legislación comparada. 3.1. Brasil. 3.2. Corea del Sur. 3.3. Estados Unidos de América. 3.4. Japón. 3.5. Nueva Zelanda. Conclusiones.

\section{INTRODUCCIÓN}

De público conocimiento es la existencia de necesidades energéticas, la falta de disponibilidad y elevados costos del carbono en Chile, tanto de la mirada económica -en detrimento del erario importándose casi la totalidad de las fuentes de energía ${ }^{1}$, cuanto desde la vista política- en relación a la producción y las complejas relaciones regionales ${ }^{2}$. Esta razón ha conformado la esencia de la motivación desarrollista de diversidad de matriz, principalmente productora de calor ${ }^{3}$. Demarcando esa senda, se develan los hidratos como una alternativa limpia ${ }^{4}$. Ubicados bajo el permafrost ${ }^{5}$ y en los sedimentos marinos de los márgenes continentales, existen estos últimos de los 500 metros a los $4 \mathrm{~km}^{6}$ de profundidad costa fuera de la Península del Taitao ${ }^{7}$ y particularmente frente a San Antonio y Talcahuano,

1 Se importa por Chile el $75 \%$ del gas natural del suministro de energía primaria. Altrichter, Christian (2011) Diversification of the Energy Matrix in the Metropolitan Region of Santiago de Chile with Focus on Renewable Energies, U. Autónoma de San Luis de Potosí y Cologne Univesity, Tesis Master, p. 29.

2 Véase Mares, David R. \& Martin, Jeremy M. (2012): "Regional Energy Integration in Latin America: lessons from Chile's experience with natural gas", en Third World Quarterly, Volume 33, Issue 1, pp. 55, 57 o 66.

3 Partain, Roy Andrew (2012) "Korea's Green Energy Laws and Methane Hydrates", Journal of Law and Policy Research, June 2012, Vol. 12. No. 2, p. 605.

4 Demirbas, Ayhan (2010) Methane Gas Hydrate, Springer, London, p. 154.

5 Capa de suelo de permanente congelamiento

6 Vera, E. y Díaz-Naveas, J. (2010): "Hidratos de gas submarino en el margen chileno", en Díaz-Naveas J. y Frutos J. (Eds.), Geología Marina de Chile, (Comité Oceanográfico Nacional de Chile, Pontificia Universidad Católica de Valparaíso, Servicio Nacional de Geología y Minería, Valparaíso, p. 62 y Departamento de prensa del Senado. En http://www.senado. cl/prontus_senado/site/artic/20130620/pags/20130620115217.html [fecha de visita $10 \mathrm{de}$ Febrero de 2014]

7 Landín, S. y Castillo, F. (2007) "Importancia de los hidratos de metano como fuente de energía”, en Conciencia Tecnológica, Instituto Tecnológico de Aguas Calientes, Núm. 033, enero-junio, p. 62. 
con potencial para satisfacer las necesidades energéticas por los próximos 100 años $^{8}$.

Comenzamos este trabajo analizando su existencia y aclarando el objeto material. Sin embargo aparece la confusión sobre su naturaleza única o dual, las que discutiremos conforme la legislación atingente. Posteriormente mostramos la idea de su concesibilidad, la que por normas constitucionales creemos yerran. Luego entraremos en las obligaciones internacionales, recordando las asumidas por Chile y las radicadas en otras fuentes, las cuales condicionan una movida en el tablero, terminado con una mirada sobre las legislaciones extranjeras de exploración y explotación del bien. Intentaremos despejar dudas y mostraremos la necesidad de legislar en vista de la extracción inminente 9 y el desarrollo nacional ${ }^{10}$, utilizando en la realización del trabajo principalmente los métodos histórico-dogmáticos en los análisis y explicándonos multidisciplinariamente.

\section{1) AsPECto BIOQUímico}

\section{1.) CONCEPTO Y AVANCES}

Para nadie es secreta la existencia de los hidratos y su relevancia ${ }^{11}$, pero se mantiene en la penumbra su conformación y distinción. Existe una respuesta química: los hidratos de gas son compuestos de agua y gases de bajo peso molecular como Propano, Butano y en particular Metano $\left(\mathrm{CH}_{4}\right)^{12}$, hidrocarburos que nacen de forma natural hasta el mo-

8 Departamento de prensa del Senado. En http://www.senado.cl/prontus_senado/site/artic/20130620/pags/20130620115217.html [fecha de visita 10 de febrero de 2014]

9 Luego del éxito de la extracción de producción en el ártico en 2012 y su investigación actual de tecnologías en la costa del golfo de EE.UU. por su departamento de energía y la Corporación Nacional Japonesa de Petróleo, Gas y Metales, entre otros. Departamento de Energía de Estados Unidos, en http://energy.gov/articles/us-and-japan-complete-successfulfield-trial-methane-hydrate-production-technologies [fecha de visita 25 de julio de 2012]. En Chile están los proyectos FONDEF D00I1104 y D04I1111. El primero comprueba la existencia de hidratos y el segundo tuvo por objeto caracterizar las reservas del recurso y determinar la factibilidad de la explotación, con resultados reservados a la fecha de la realización del trabajo.

10 Baldo Prokurica presentó un proyecto de acuerdo para que el gobierno pueda disponer de los recursos para realizar una exploración detallada. Disponible en http://www.senado.cl/ prontus_senado/site/artic/20130620/pags/20130620115217.html [fecha de visita 10 de Febrero de 2014]

11 Véase Doc. N.U. A/59/122, p. 21 y Vera y Díaz-Naveas (2010) 62.

12 Demirbas (2010) 59 y Sloan, Dendy, et. al. (2011) Natural Gas Hydrates in Flow Assurance, Elsevier, Oxford, p. 2. Ver Vera y Díaz-Naveas (2010) 62. 
mento ${ }^{13}$, principalmente de origen microbiano, y termogénico, perteneciendo al subconjunto de los compuestos de inclusión ${ }^{14}$. Estos compuestos forman una estructura similar a una jaula ${ }^{15}$ en la que queda atrapado el gas, constituyéndose en un sólido cristalino. Expresado de otra forma, son sólidos, que consisten en una molécula de gas rodeada por una jaula de moléculas de agua ${ }^{16}$ (un compuesto que contiene agua ${ }^{17}$ dicen otros), ocurriendo a profundidad, presión y temperatura especiales, sin las cuales no pueden mantenerse ${ }^{18}$.

Aunque hay quienes insisten en que los minerales son sólidos ${ }^{19}$, es de conocimiento y uso general catalogar a los hidrocarburos como minerales combustibles ${ }^{20}$. De esta manera, el hidrato es compuesto por hidrocarburos más una jaula compuesta por agua congelada, naciendo la confusión entre su entendimiento como recurso único y especial o dos diferentes, no habiendo acuerdo. Sí se tiene claro que deja de ser un compuesto al desaparecer las condiciones seńaladas, disociándose y perdiendo su unicidad.

Sobre su búsqueda y desarrollo extractivo no se utiliza aún para abastecer comunidades. Hay avances en Estados Unidos y Japón, con investigación, estudios y evaluaciones en Alaska y el Golfo de México por una parte y Nankai por otra, habiendo búsqueda y desarrollo ${ }^{21}$ desde 2001. El

13 Véase v.g. Parkes, J., et al. (2009) "Culturable Prokariotic diversity of deep, Gas Hydrate Sediments: First Use of a Continuous High-Pressure, Anaerobic, Enrichment and Isolation System for Subseafloor Sediments (DeeplsoBUG)", Society for Applied Microbiology, Enviromental Microbiology, Vol. 11, Issue 12, pp. 3140-3153, en que se estudiaba la manipulación de entes que forman hidratos.

14 Véase Demirbas (2010) 81, y Sloan et al. (2011) 9 y 13.

15 Clatratos, del latín encerrado con barras. Demirbas (2010) 86.

16 Aunque hemos de decir que existen clasificaciones, todas ellas por cierto tienen el mismo criterio diferenciador. Sloan et al. (2011) 2 y 3 y Demirbas (2010) 59 y 93.

17 Carrol, John (2009) Natural Gas Hydrates: A Guide for Engineers Elsevier, Oxford, p. 1.

18 Profundidad sobre $500 \mathrm{~m}$, alta presión y baja temperatura. Demirbas (2010) 80.

19 Vg. Walker, Sally (2007) Minerals, Lerner Publications, p. 7

20 Vg. Mongillo, John y Zierdt-Warshaw Linda (2000), Encyclopedia of environmental science, University Rochester press, p. 247; United States Congress (1979) Management of fuel and nonfuel minerals in Federal land: current status and issues, Office of Technology Assessment, p. 293; Ley sobre hidrocarburos y demás minerales combustibles de Venezuela, del 13 de julio de 1921, Art. 1. Incluso hay departamentos de secretarías de estado, como en Tailandia, llamados departamento de minerales combustibles que se ocupa del petróleo principalmente, o el departamentos de minas y geología del Ministerio de Industria de Nepal.

21 Según la Japan Gas, Oil and Metals National Corporation (JOGMEC), que es una empresa estatal dedicada a la investigación y desarrollo en el área energética. https://www.jogmec. go.jp/english/ [fecha de visita 20 de enero de 2012]. 
programa de Japón parece ser el más avanzado 22 , lo que hace ver la superación de la limitante económica ${ }^{23}$.

\section{2) IMPORTANCIA ECONÓMICA, MEDIO AMBIENTE Y SEGURIDAD}

Los compuestos caen en la clasificación de recursos naturales ${ }^{24}$, con un uso potencial, siendo fuentes globales y primarias de energía no renovables al ser incapaces de volver a su estado físico anterior ${ }^{25}$. Los ubicados en territorio nacional representarían cerca del 3 por 100 del total mundial $^{26}$, con un potencial de satisfacción nacional de 100 años ${ }^{27}$, conteniendo por unidad de masa dos veces más carbono que el carbón, gas natural y el petróleo combinados ${ }^{28}$.

22 Siendo el mayor importador neto de gas natural al 2010 y el estado que más paga por importación de gas natural al 2008. International Energy Agency (IEA) (2011) Key World Energy Statistics, OECD/IEA, París, disponible en $<<\mathrm{http}: /$ www.iea.org/textbase/ nppdf/free/2011/key_world_energy_stats.pdf $>>$ p. 13 y 41. Se pueden agregar los desarrollos de India, Rusia, Corea del Sur, China (con el sumergible Jiaolong además del Ocean's No 6. La Tercera, 26 de junio de 2012, http://view.koreaherald.com/kh/view. php?ud=20120710001337\&cpv=0, http://www.atimes.com/atimes/southeast_asia/ mg15ae01.html [al 2 de marzo de 2013]. Actores de menor importancia son Canadá, la Unión Europea, Taiwán, España, Chile, Nigeria, Colombia, Nueva Zelandia y Perú. Véase Ferrer FougÁ, (1999) p. 110; http://www.jogmec.go.jp/english/index.html, [al 21 de abril de 2011]; Demirbas (2010) 133 y 134.

23 Se había expresado como un limitante del crecimiento tecnológico el costo. Los proyectos sobre instalaciones fuera de la costa frecuentemente excedían el billón de dólares EE.UU. SlOAN et al. (2011) 1. En 2013 la JOGMEC japonesa lo consiguió en sus costas con expectativa de producción en seis años. Información oficial, 12 de marzo de 2013, JOGMEC. http://www.jogmec.go.jp/english/information/news_release/docs/2012/newsrelease_130312.pdf [fecha de visita 2 de abril 2013]. Esto podría demostrar la destrucción de las dudas sobre su extracción y comercialización. VARGAS, Rocío y VALDÉs, José Luis (edit.) (2006) Recursos Naturales Estratégicos, UNAM, p. 11.

24 Por su mirada antropocéntrica. Existen quienes no están de acuerdo. Melo Moreno, Vladimir (2005), Indentidades 10, Norma, Bogotá, p. 48, y Revista Forbes en http://www.forbes. $\mathrm{com} /$ sites/quora/2012/07/09/how-many-years-of-oil-do-we-have-left-to-run-our-industrialcivilization-keeping-in-mind-that-oil-is-a-resource-and-has-an-economical-end/ [fecha de visita 18 de Julio de 2012].

25 Melo Moreno et al. (2005) 48 y Longás, Juan Carlos (2009) “los problemas ambientales", en Bilbao, Javier, et al. (coord.), Temas de Economia Mundial, Madrid, p. 150.

26 La Tercera, sábado 14 de septiembre de 2013.

27 Departamento de prensa del senado, http://www.senado.cl/prontus_senado/site/artic/20130620/pags/20130620115217.html [fecha de visita 10 de febrero de 2014] y las necesidades globales energéticas por los próximos mil ańos y representando un estimado de más de un 50 por 100 de todas las reservas de combustible de carbono. Demirbas (2010) V y 114.

28 Smil, Vaclav (2008) Energy in Nature and Society: General Energetics of Complex Systems, Massachusetts Institute of Technology Press, p. 215. Otros muestran cifras similares a las reservas de carbón orgánico. Milkov, A.V. (2004) "Global estimates of hydrate-bound gas in marine sediments: how much is really out there?" , en Earth-Science Reviews, Núm. 66, p. 195. Aún así se calcula que los depósitos oceánicos de hidrato almacenan entre 2 y 10 billones de toneladas métricas de carbono como metano. United Nations Enviroment Program (2008): UNEP yearbook 2008, UNEP, Kenya, p. 42. 
Teniendo generalmente un impacto medioambiental y considerándose la fuente más grande de combustible fósil ${ }^{29}$, algunas estimaciones señalan que hay 3.000 veces la cantidad de $\mathrm{CH}_{4}$ en las formaciones de hidratos que lo encontrado en la atmósfera ${ }^{30}$; un tema preocupante, ya que sería cerca de 20 veces más efectivo que el dióxido de carbono $\left(\mathrm{CO}_{2}\right)$ como gas invernadero ${ }^{31}$, pudiendo aumentar dicho efecto ${ }^{32}$. Se agrega que su liberación incluso controlada puede producir desprendimientos de tierras, peligros a los conductos, cables submarinos ${ }^{33}$ y gasoductos ${ }^{34}$, perturbaciones aéreas ${ }^{35}$, amenazas a los montes submarinos ${ }^{36}$ o la acidificación de las aguas ${ }^{37}$.

Además existe necesidad de entender y proteger la biota específica sustentadora de ecosistemas únicos como los respiraderos hidrotérmi$\cos ^{38}$, pudiendo producirse un daño ambiental irreparable por extracciones de genes y gas ${ }^{39}$. Incluso la disociación del hidrato ya pudo haber extinguido biota béntica y disuelto el oxigeno marino ${ }^{40}$.

Existiría también la posibilidad de extraer agua dulce de ellos ${ }^{41}$. Esto no es menor, puesto que las reservas de agua bebestible decaen progresivamente $^{42}$ y si consideramos las cifras de carencia, saneamiento, muertes

29 Demirbas (2010) 1.

30 Kenneth, J.P., et al. (2003) Methane Hydrates in Quaternary Climate Change: The Clathrate Gun Hypothesis, AGU Books Board, American Geophysical Union, Washington, p. 90.

31 Ponting, Clive (1992) Historia Verde del Mundo, Paidós, Barcelona, p. 518 e Hilgenkamp, K. (2006): Enviromental Health: Ecological Perspectives, Jones and Bartlett, London, p. 142. Se manifiesta que llegaría a la multiplicación por 21 e incluso 23 en su efecto de calentamiento, aunque el metano es el fósil más limpio, emitiendo menos $\mathrm{CO}_{2}$ que el petróleo o el carbón por unidad de energía. Demirbas (2010) 68 y United Nations Enviroment ProGRAM (2008) 42.

32 Kenneth et al., (2003) 4, 113 y 167 y Demirbas (2010) 128.

33 Exposición de Allison, E., Documento O.N.U. A/59/122, párr. 70.

34 En Chile esto es conocido incluso en la legislación técnica sobre prevención del congelamiento de tuberías de gas, decreto ley 66 del Min. de Economía promulgado el 2 de julio de 2007 que aprueba reglamento de instalaciones interiores y medidores de gas, Art. 46, Núm. 2.4. Demirbas, (2010) 81.

35 May, D. y Monaghan, J. (2004) “Can a Single Bubble Sink a Ship?”, Journal of Scientific Exploration, Universidad de Monach, Vol. 18, No. 2, pp. 307-312.

36 Doc. UNEP/CBD/SBSTTA/13/4, p. 16.

37 Biastoch, A., et al. (2011): "Rising Arctic Ocean temperatures cause gas hydrate destabilization and ocean acidification", en Geophysical Research Letters, Vol. 38, Num. 8, 16 april, p. 5.

38 Con tapetes microbianos, cangrejos y anélidos como el methane ice worm. CANET et al. (2010) p. 7.

39 Véase OCEANA (2006) p. 29.

40 Demirbas (2010) 129.

41 De cada 10 hidratos, 8 contendrían agua. Allison, Edith, Doc. U.N. A/59/122, párr. 70 y 71. La descomposición de $1 \mathrm{~m}^{3}$ de hidrato de metano produciría $164 \mathrm{~m}^{3}$ de metano gaseoso y $0,8 \mathrm{~m}^{3}$ de agua líquida Véase Doc. A/59/122, p. 21 y Díaz-Naveas y Frutos (edit.) (2010) 62.

42 V.g. Raven, P., et al. (2011) Enviroment, $8^{\text {th }}$ Edition, John Wiley and Sons, inc., New York, pp. 274-276. Aunque hay postulados señalando que el acceso a agua potable ha aumentado, cumpliéndose con las metas del milenio. UNICEF and World Health Organization 
y pérdidas económicas ${ }^{43}$, nos hallamos frente a un motivo de preocupación ${ }^{44}$.

\section{2) ASPECTO EXEGÉTICO}

\section{1) EL GAS: INAPLICABILIDAD DEL ESTATUTO MINERO CONCESIONAL}

Por su importancia, y en una medida lógica históricamente ${ }^{45}$, la Constitución Política de la República (C.P.R.) expresa que el Estado tiene dominio absoluto, exclusivo, inalienable e imprescriptible de todas las minas, comprendiéndose en estas (...) hidrocarburos y las demás sustancias fósiles (...), sin importar si la riqueza se encuentra en la superficie o debajo de ella ${ }^{46}$. De esta forma, no solo se dedica a establecer el dominio sobre las minas, dejando clara su calidad de bienes fiscales ${ }^{47}$, sino que además manifiesta los atributos amplísimos e inherentes de que está dotado aquel derecho respecto del Estado como sujeto activo, elemento manifestado en toda la legislación atingente ${ }^{48}$, y dando al término mina una concepción amplia, lo que parece confirmado por la ciencia dura como vimos.

Este último entendimiento lato, que va en contra de los acuerdos jurídicos clásicos ${ }^{49}$, creemos se muestra con mayor brillo al estimar las diferencias con la concepción de la Ley 17.450 de 1971 que reformó la Constitución de 1925 en cuanto a propiedad minera, estableciendo la propiedad real del estado sobre ella, pero que además enumeraba las propiedades estatales, distinguiendo explícitamente entre hidrocarburos, covaderas y minas, situación que no ocurre en la actualidad. Aún más, en

(2012) Progress on drinking water and sanitation 2012 update, WHO-UNICEF, New York, p. 6.

Preámbulo, Resolución N.U. sobre derecho humano al agua y el saneamiento. Doc. N.U. A/64/L.63/Rev.1.

44 Los índices de cobertura de agua urbana en Chile son altos, sin embargo las reservas naturales del recurso están cediendo y la cobertura rural es deficiente. UNICEF and World Health Organization, (2012) 13 y National Geographic, http://www.nationalgeographic.es/noticias/medio-ambiente/calentamiento-global/1112-melting-glaciers-mean-double-trouble-forwater-supplies [fecha de visita 23 de julio de 2012].

45 Nos referimos al proceso de nacionalización del cobre.

46 El llamado Dominio Patrimonial o Real. Actas Oficiales Comisión Constituyente, Sesión 170a, 27 de Nov. de 1975, conclusión a); Sesión 171ª 4 de Dic. de 1975, entre otras Art. 19, Número 24, Párrafo 6. Ver además art. 1 del Código de Minería.

47 Vergara, A. (1992) Principios y Sistema del Derecho Minero: estudio histórico-dogmático, Editorial Jurídica, Santiago, p. 210.

48 Vg. Ley 9.618, modificado por el D.F.L. 1 de Minería, art. 2, que crea la Empresa Nacional del Petróleo.

49 Se expresa por la doctrina que el concepto de mina es todo depósito natural de sustancias del reino mineral, y que los hidrocarburos están comprendidos solo determinadamente por estimarlo conveniente. Vg. Ossa, J.L. (2007) Tratado de Derecho de Minería Tomo I, Cuarta Edición, Editorial Jurídica de Chile, Santiago, p. 55. 
las propias Actas Constitucionales de la carta de 1980, al discutirse sobre el tema de la propiedad minera, se deja claro que la enumeración de minas contenida es genérica y no taxativa ${ }^{50}$.

Por su parte el párrafo 7 del número 24 manifiesta que le corresponde a la ley determinar qué sustancias de aquellas referidas anteriormente, exceptuados los hidrocarburos líquidos y gaseosos, pueden ser objeto de concesiones mineras ${ }^{51}$, negando así cualquier posibilidad de entregar derechos de aprovechamiento sobre el gas contenido en los hidratos, lo que tiene perfecta lógica conforme al art. 19, Núm. 21, Párr. $1^{52}$. Antecedente de esta inconcesibilidad y sus motivaciones económicas se encuentran en la historia legislativa y un ejemplo es la reserva de los hidrocarburos al Estado en $1926^{53}$.

En los caso de yacimientos que no son susceptibles de concesión minera, pueden ejecutarse exploraciones, explotaciones o beneficios de ellos directamente por el Estado o por sus empresas, o por medio de concesiones administrativas o de contratos especiales de operación (CEO), siendo este último caso el regulado por el Decreto Ley $1.089^{54}$. Aún más, la norma constitucional precisa que se aplicarán dichas tareas de exploración, explotación o beneficios a los yacimientos de cualquier especie mientras existan en aguas marítimas sometidas a jurisdicción ${ }^{55}$. En el mismo sentido interpretamos yacimiento desde un punto de vista técnico ${ }^{56}$, incluyendo todo lugar donde se extienden sustancias o elementos en cantidades importantes de forma natural, para extraerlos con fines económicos y/o intelectuales, y que incluyen temas de interés nacional.

Esta norma es reiterada por la Ley Orgánica Constitucional sobre Concesiones Mineras ${ }^{57}$, (LOCCM) que en su Art. 3, Inc. 4 repite la norma constitucional sobre inconcesibilidad de los hidrocarburos mencionados y agrega otras condiciones del yacimiento para otorgar la concesión, entre ellos que no correspondan a yacimientos existentes en aguas

50 Actas Oficiales Comisión Constituyente, Sesión 180a , 8 de enero de 1976, comentario del señor Samuel Lira (sobre la posibilidad de hacerse dueño el estado de las arcillas superficiales). Esta idea pareciese reafirmada al acordarse el texto final del párrafo, el cual entrega la excepción a la regla: las arcillas superficiales.

51 Acerca de las concesiones y su naturaleza evitamos referirnos; doctrina existe de sobra.

52 La base del sistema económico, y por lo tanto, también del de concesiones, recae en el sistema de aseguración constitucional del derecho a desarrollar actividad económica cualquiera sea esta, mientras no sea contraria, entre otras cosas, a la seguridad nacional, respetando las normas legales que la regulen.

53 Ossa (2007) 69, acerca de la Ley número 4.109 de 1926.

54 Texto refundido, coordinado y sistematizado por el D.F.L. 2 de Minería de 1986.

55 Art. 19, Número 24, párrafo 10, Constitución Política de la República (C.P.R.).

56 En inglés deposit, unánimemente aceptada en la comunidad científica para los hidratos. V.g. Demirbas (2010) pp. 79 y 80.

57 Ley Orgánica constitucional (L.O.C.) 18.097 del 7 de enero de 1982, sobre concesiones mineras. 
jurisdiccionales o están ubicados en el subsuelo marino con acceso desde tierra, lo que termina por negar la concesión minera del gas marino.

Acerca de las diferentes normas relativas a las emisiones de gases, no existe ninguna relativa a los hidratos. Las limitantes en su uso están dadas respecto del área y sus fuentes ${ }^{58}$, aunque hay decretos que se deben tener en cuenta como sobre seguridad en plantas de gas licuado ${ }^{59}$ y manifestaciones expresas de la autoridad sobre sus facultades de otorgar CEO a terceros sobre el metano sin distinciones ${ }^{60}$. Sobre estos, es cierto que actualmente se desarrolla extracción de metano ${ }^{61}$, pero nunca con las previsiones generales de extracción de los hidratos.

En resumen, si se estimaran elementos diferentes, el principal contenido del agua que conforma la parte exterior de un hidrato es un bien fiscal minero combustible no concesible y, si se estima como una unidad, no es objeto de concesión por su ubicación marina y por los derechos de propiedad estatal. El problema podría aparecer en áreas de permafrost si alguien estimara el agua como elemento fundamental, lo que trataremos infra.

\section{2) El AGUA: ALEJÁNDOSE DEL CÓdigo Y LA CONCESIÓN}

Todas las aguas son bienes nacionales de uso público ${ }^{62}$, siendo incomerciables en el derecho privado. Al no distinguir entre aguas ni definir qué se entiende por tal, es la Química la que lo hace ${ }^{63}$, constituyéndose en un compuesto de oxígeno e hidrógeno, en forma líquida, gaseosa o sólida, último caso el de los hielos ${ }^{64}$. Al igual que los hidratos, en el agua pueden

58 Vg. Decreto 130 establece normas de emisión de monóxido de carbono (co), hidrocarburos totales (hct), hidrocarburos no metánicos (hcnm), metano (ch4), óxidos de nitrógeno (nox) y material particulado (mp) para motores de buses de locomoción colectiva de la ciudad de Santiago

59 Decreto 67 del Min. de Energía, que aprueba reglamento de seguridad de plantas de gas natural licuado.

60 Vg. Decreto 67, Min. de Minería, que establece requisitos y condiciones del CEO bloque dorado Riquelme para la exploración y explotación de yacimientos de hidrocarburos que el Estado de Chile suscribirá con la Empresa Nacional del Petróleo y Methanex Chile S.A. en la Duodécima Región de Magallanes y Antártica Chilena.

61 Decreto 3 Min. de Minería establece requisitos, términos y condiciones del CEO para la exploración y explotación de yacimientos de hidrocarburos que el Estado de Chile suscribirá con Layne Energía Chile S.A. bloque Arauco Octava Región del Biobío, o el decreto 29 del Min. de Minería que establece requisitos, términos y condiciones del contrato especial de operación para la exploración, explotación o beneficio de yacimientos de hidrocarburos que el Estado de Chile suscribirá con Cardinal Resources inc. y Empresa Nacional del Petróleo.

62 Art. 595 del Código Civil (C.C.): Se llaman bienes nacionales aquellos cuyo dominio pertenece a la nación toda. Si además su uso pertenece a todos los habitantes de la nación... se llaman bienes nacionales de uso público o bienes públicos. Art. 589 del C.C. La idea es repetida por el Código de Aguas, art. 5.

63 Art. 21 del C.C.: Las palabras técnicas de toda ciencia o arte se tomarán en el sentido que les den los que profesan la misma ciencia o arte (...).

64 Tortolero (2000) p. 14. 
separarse sus elementos constitutivos ${ }^{65}$, pero esto no la hace una sustancia tratada de manera independiente en la química ni en lo legal.

Revisando los cuerpos cuyo objeto es el agua, aparece la aplicación del Código de Aguas y la Concesión Marítima. El primero destaca su propio ámbito de aplicación, no recayendo en las marítimas ${ }^{66}$, impidiendo la existencia de derechos de aprovechamiento del agua de los hidratos y reiterando su calidad de bien nacional de uso público en el Art. 5.

En segundo lugar, el Decreto Supremo número 2 (D.S. 2), del año 2005, sobre Concesiones Marítimas ${ }^{67}$ señala en su Art. 3 la facultad de carácter privativo del Ministerio de Defensa y de la Dirección General de Territorio Marítimo y Marina Mercante (DIRECTEMAR) ${ }^{68}$ el conceder el uso particular, en cualquier forma, de los terrenos de la playa (...), porciones de mar, fondo de mar, dentro y fuera de las bahías. Esto como se ve es contrario a las definiciones entregadas por autores que estiman inherente el derecho a goce como facultad entregada al solicitante ${ }^{69}$. Las concesiones marítimas expresamente nacen y se mantienen como una forma de establecer derechos de uso sobre áreas declaradas bienes nacionales de uso público, mas no se pronuncia respecto de la extracción, esto es gozar del producto contenido en ellas, haciendo prevalecer dicha norma la clasificación doctrinaria y legal de los atributos del dominio ${ }^{70}$ en que el uso se diferencia del goce, existiendo únicamente dominio sobre el derecho de uso mientras dure la concesión.

Alguien podría alegar que sí se explota y un ejemplo son las concesiones a favor de las plantas desalinizadoras ${ }^{71}$. Parece difícil tal comparación, puesto que en nuestro caso se estaría dando una utilización que implica su detrimento físico debido a su cantidad limitada, destruible o agotable, a diferencia del agua salina que se caracteriza por su inmensa

65 Por electrólisis. SeEse, William S. \& Daub, William (2005), Quimica, Octava edición, Pearson, México, p. 408.

66 Art. 1, inc. 1 del Código de Aguas.

67 Que sustituyó al Decreto Ministerial 660 de 1988, precedido este último por el D.F.L. 340 de 1960, y que está amparado en la llamada Ley de Concesiones -Decreto № 900 del Ministerio de Obras Públicas-, art. 1, principalmente.

68 Que son los dos entes inmiscuidos en el procedimiento de concesión marítima.

69 Concesión maritima es un acto que (...) crea derechos a favor de un particular sobre determinados bienes nacionales de uso público o fiscales, otorgándole su uso y goce por un tiempo definido, aunque la misma no pierde de vista el requisito de la realización de actividades sin menoscabo al bien común. Navarrete, A. (1991) "Régimen Jurídico de las Concesiones Marítimas", Revista Chilena de Derecho, Vol. 25, No. 4, pp. 953-991pp. 965.

$70 \quad$ Claro (1992) p. 335.

71 Para 2010 existían 3 plantas de ese tipo en el norte del país y otras 7 como proyectos. Ponencia de Mario Gonzales, Desalación para suministro de agua potable en el norte de Chile, Aguas Antofagasta, II Seminario Internacional de Desalación en Antofagasta, 29 y 30 noviembre y 1 diciembre 2010, disponible en http://www.desalchile.cl/anterior/documentos/23.ADASAMGP.pdf 
cantidad $^{72}$; es eso lo que hace variar esencialmente el derecho de uso del goce en referencia a los productos de los yacimientos, lo cual parece más claro al ver la facultad-obligación de la secretaría de gobierno respectiva de controlar, fiscalizar y supervigilar el mar territorial ${ }^{73}$. En tal sentido se entiende la norma del Art. 4 del mismo Decreto Supremo sobre extracción de materiales, una autorización cuyo respaldo parece ser el facilitamiento del uso, protección a terceros y su reducción en $\operatorname{costos}^{74}$.

De esta forma la ley impide la existencia de derechos de aprovechamiento del agua de los hidratos marinos, donde el Estado tiene dominio y derechos de soberanía ${ }^{75}$. ¿Qué es lo que pasa con el permafrost ${ }^{76}$ ? Sabemos se podrían establecer derechos reales de aprovechamiento de agua subterránea ${ }^{77}$, pero esto no tendría importancia radical en principio. Los hidratos no pueden dividirse fácilmente ${ }^{78} \mathrm{y}$ por lo tanto los derechos podrían convivir mientras no haya un tratamiento especial por la legislación, al ser el Estado quien tiene el dominio del hidrocarburo. Si existiesen derechos sobre los hielos, no podrían ser extraídos ni gozados autónomamente. Decíamos en principio, porque el argumento de fondo es que existen obligaciones que los particulares no pueden cumplir y en las cuales no deberían tener incidencia autónoma porque atañen al Estado. Pero a su vez, extraídos por este, podrían ejercerse acciones, demandando incluso perjuicios, aunque quedando inalterable la lógica fiscal y solo aplicándose la responsabilidad extracontractual del Estado.

Veremos que desde el punto de vista internacional hay que considerar que la extracción del hidrato sin aprovechamiento de su agua podría ser una falta a la institución de la propiedad, además de otras relativas al gas.

72 Del 70\% del agua que constituye la superficie de la tierra, la mayor parte es oceánica, de ella solo el 3\% es dulce y de ella únicamente el 1\% es aprovechable. Anaya, M. \& Martínez, J.J. (2007) Problemática del agua en el mundo, manual sobre sistemas de capacitación y aprovechamiento del agua de lluvia para el uso doméstico y consumo humano para América Latina y el Caribe, Centro Internacional de Demostración y Capacitación en Aprovechamiento del Agua de Lluvia- PNUMA, p.6.

73 Art. 2 del Decreto Supremo 2 o Reglamento concesiones marítimas.

74. ...corresponderá especialmente a la Dirección el autorizar la extracción de materiales varios que se encuentren en las áreas sujetas a su fiscalización y control, como asimismo, autorizar en esos lugares la instalación temporal de carpas u otras construcciones desarmables, de avisos de propagan$d a$, de boyas y atracaderos para embarcaciones menores, de colectores de semillas, de balsas para bañistas y boyarines destinados a delimitar áreas de recreación. Art. 4, Decreto Supremo 2.

75 Arts. 593 y 596 C.C.

76 Los estudiosos lo han descartado, ubicando hidratos en eso lugares solo en Alaska, Siberia y el norte de Canadá. López Casillas, Alberto (2004) "Hidratos de gas", Energías y medio ambiente, Ramos Castellanos, Pedro, Universidad de Salamanca, 2004, p.51.

77 Art. 2, 58 y sgtes. del Código de Aguas.

78 Sobre el procedimiento de extracción y división hay varias técnicas, con éxito conocido solo la del reemplazo por dióxido de carbono. Demirbas (2010) 81 y 147. 


\section{3) EXPRESIÓN DEL BIEN COMÚN Y FUNCIÓN SOCIAL}

Si el Estado está obligado a promover el bien común y la propia ley debe mostrar las obligaciones del derecho de propiedad que derivan de su función social ${ }^{79}$, aunque no se refiere directamente a esta, al menos hay un acercamiento a la idea de la necesidad de una ley como manifestación soberana por excelencia, señalando obligaciones generales. La posición es válida si consideramos las implicaciones de la extracción expresada, no pudiendo hacerlo un particular autónomamente, y es coincidente con la opinión que la institución de la propiedad parece ir decantando hacia una mirada más común, lo que se hace patente en la legislación comparada donde se conceptualiza en vista de sus resultados sobre necesidades sociales sin distinción del titular de dicho derecho ${ }^{80}$. Así, el Estado debe manifestarse de la forma idónea para ejercer un derecho de dominio que tiene incidencias generales.

Esto no es extraño. Contando con una expresión histórica de voluntarismo general ${ }^{81}$ y manifestado en la misma carta de N.U. el reconocimiento de la soberanía popular ${ }^{82}$, pareciese que un bien de este calibre no podría tener otra finalidad que favorecer directamente a los destinatarios de la ficción estatal, con una naturaleza acorde. Es decir, expuesto el vínculo con la democracia, procede el bien común de Rousseau, señalado primitivamente por Aristóteles con la propiedad moderada y suficiente como expresión de la democracia perfecta, Vitoria en su Communitas $o r b i^{83}$, y Santo Tomás con la finalidad de la ley ${ }^{84}$, idea que es plasmada en la constitucionalidad de fin del S. XVIII, la declaración de los derechos

Vg. Constitución Alemana (Grundgesetz fur die Bundesrepublik Deutschland) señala en su Art. 14 la propiedad obliga. Su uso debe servir por igual al bienestar de la mayoría; la Constitución Bávara, Art. 151, expresa toda actividad económica sirve al bien común; y la Constitución española habla de La función social de estos derechos (propiedad y herencia) delimitará su contenido, de acuerdo con las leyes. Felber, Christian (2012) La economía del bien común, Barcelona, Planeta, p. 15.

81 Rousseau y los Jacobinos A diferencia del la soberanía nacional, como en la declaración de derechos del hombre y del ciudadano.

82 Preámbulo Carta de las Naciones Unidas. Nosotros los pueblos de las naciones unidas... Hoy hay un equilibrio entre las concepciones radicales del pueblo y de la nación. Flores, Marcello (coord.), diccionario básico de derechos humanos cultura de los derechos en la era de la globalización, FLACSO, México, 2009, pp. 306 y 307

83 Ferrajoli, Luigi (2009) derechos y garantías la ley del más débil, Sexta Edición, Trotta, p.128. (...) el principe (...) debe encaminar todos sus actos al bien común... La autoridad (...) debe emplearse para el bien de la república (...). Las leyes (...) deben ser promulgadas para el bien común (...).VITORIA, Francisco de, reelecciones de indios y del derecho de la guerra, reelección posterior de los indios acerca del derecho de guerra los españoles en los bárbaros, 1928, pp. 217-219 y Rousseau, Juan, El contrato social, Porrúa, 2006, p. 17 y sgtes. 
del hombre y del ciudadano ${ }^{85}$ o la Constitución de los Estados Unidos de América ${ }^{86}$.

El dominio sobre el derecho de aprovechamiento de aguas en las condiciones señaladas no podría preferirse por sobre consideraciones de orden público, bien común y función social; bienes, objetivos y causas finales que pesan más en la balanza de los hidratos.

\section{4) UNA NATURALEZA JURÍDICA}

Vemos que el hidrato es un bien -al considerar su utilidad inmediata y relevante cual es la extracción energética-, corporal, mueble ${ }^{87}$, indivisible ${ }^{88}$, incomerciable por su destino mientras se mantenga dicha débil unicidad física que es dual en sus elementos constitutivos, pero que no está integrado explícitamente en el ordenamiento y, conforme a los estatutos nacionales, no puede ser objeto de derecho de dominio o comercio privado considerando los elementos seńalados. La única cosa incorporal nacida serían derechos reales muebles de aprovechamiento de agua subterránea y concesión marítima, ambos en último caso no aplicables por argumentos de orden público. Es decir, en el peor de los escenarios podría ser por subsumisión del gas al agua (si los estimáramos dos elementos diferentes y esta última por algún motivo más relevante que la primera) bien de uso público, lo que vemos improbable por la relevancia del gas, la imposibilidad de la concesión y de una desafectación, y el no uso generalizado propio de este tipo de bienes.

Parece ser un solo bien físicamente con preponderancia del gas en lo jurídico ${ }^{89}$. Las intenciones del uso del agua no determinarían naturaleza al existir propiedad estatal ${ }^{90}$. 


\section{5) OBLIGACIONES ESTATALES}

\subsection{1) La protección medioambiental}

Los hechos explicados develan que la exploración y explotación de hidratos inducen a alteraciones, contaminación, daño y/o detrimento al patrimonio ambiental, incluso más allá de las fronteras. Aun cuando Chile no asumió responsabilidades específicas en Kioto ${ }^{91}$, sí manifiesta una tendencia concurrente sobre la protección medioambiental, en particular la emisión de gases como en el Convenio de Viena para la Protección de la Capa de Ozono ${ }^{92}$ y otros instrumentos aceptados por la generalidad ${ }^{93}$. Este obliga a los Estados a adoptar las medidas legislativas o administrativas adecuadas y cooperarán en la coordinación de las politicas apropiadas para controlar, limitar, reducir o prevenir las actividades humanas bajo su jurisdicción o control en el caso de que se compruebe que estas actividades tienen o pueden tener efectos adversos como resultado de la modificación o probable modificación de la capa de ozono ${ }^{94}$, señalando al metano como sustancia que afecta el ozono en su anexo I.

La obligación de cooperación en la coordinación de las politicas apropiadas, pareciese dejar la puerta abierta a quienes gustan de los CEO para la implementación de cualquier extracción, al incluir medidas administrativas. Pero vemos que aparecen complicaciones. La primera es que debido a los riesgos que entraña la acción ${ }^{95}$, la responsabilidad objetiva del Estado (en el caso de actividades extremadamente peligrosas y/o directamente dańosas) aparece como un principio general de derecho, al encontrarse en todas las legislaciones locales ${ }^{96}$, sea se produzca el daño entre fronteras o

91 Protocolo de Kioto. Chile está dentro de los países del anexo 2.

92 Convenio de Viena para la Protección de la Capa de Ozono, promulgado el 28 de septiembre de 1989, Decreto 719 del Min. de Relaciones Exteriores.

93 Como el Protocolo de Montreal relativa a las sustancias que deterioran la capa de ozono, promulgado mediante el decreto supremo $N^{\circ} 238$, de 1990, del Ministerio de Relaciones Exteriores.

94 Art. 2, letra b.

95 La Carta de Derechos y Deberes Económicos de los Estados responsabiliza a todos ellos de la protección, preservación y el mejoramiento del medio ambiente para las generaciones presentes y futuras. Véase Drnas de Clément, Z. (2001): "Los principios de Prevención y Precaución en Materia Ambiental en el Sistema Internacional y en el Interamericano”, Jornadas de Derecho Internacional, Secretaría General de la Organización de Estados Americanos, OEA, Washington, p. 82.

96 Soто, M. (1996) "General Principles of International Environmental Law", ILSA Journal of International and Comparative Law, Vol. 3, p. 203 y Orrego, F. (1991) "La evolución de la responsabilidad internacional del Estado en el derecho internacional a la luz de los nuevos criterios para la protección del medio ambiente", en Sociedad Chilena de Derecho Internacional, Estudios 1991, Santiago, p. 94; reconociéndose por la Comisión de Derecho Internacional (CDI). Párrafo 3, del artículo 19 del Proyecto de responsabilidad del Estado por hechos internacionalmente ilícitos. 
fuera de las jurisdicciones 97 , y en Chile particularmente el Estado tiene además el deber de tutelar la preservación de la naturaleza, existiendo la acción de protección para asegurar su debida protección ${ }^{98}$, incluso para aquellos que no habitan cerca del lugar físico, al ser un derecho colectivo público $^{99}$, y en vista de un daño simplemente potencial ${ }^{100}$.

Sin embargo, asumiendo lo anterior, si estimáramos que hay solo un riesgo dudoso, cualquier respuesta y acción por parte del Estado debe ser particularmente cuidadosa, anteponiendo por lo menos la precaución necesaria ${ }^{101}$ para evitar el peligro que podría significar el aumento explosivo de gases efecto invernadero como el metano ${ }^{102}$, la destrucción de materiales y la biota específica asociada a los hidratos, el patrimonio ambiental, mediante el desarrollo e implementación de las mejores técnicas disponibles para evitar el daño ambiental ${ }^{103}$. Lo expresado se entiende mejor mediante la Declaración de Río ${ }^{104}$ y el Convenio sobre la Diversidad Biológica $(\mathrm{CDB})^{105}$. Los Estados tienen la obligación de actuar en interés de la

Ningún Estado tiene derecho a usar o permitir el uso de su territorio de manera tal que las emanaciones de gases causen daños al territorio de otro Estado, o a los bienes o personas residentes en el mismo. Moyano Bonilla, César (1995) "Derecho a un Medio ambiente Sano", Boletín Mexicano de Derecho Comparado, Serie Año XXVIII, Núm. 82, enero-abril, pp. 252 y 253. C.P.R., Art. 19, núm. 8 y 20.

99 Resolución del Caso Trillium (1997). Corte Suprema, 19 de marzo de 1997, Corte de Apelaciones de Santiago 10 de diciembre de 1996. Horvath Kiss, Antonio y otros con Comisión Nacional del Medio Ambiente (Recurso de Protección), Revista de Derecho y Jurisprudencia y Gaceta de los Tribunales, Núm. 1-1997, enero 1997.

100 Corte Suprema, Revista Fallos del Mes, Núm. 403, junio, 1992, p. 311.

101 Al no existir certeza científica unánime, no hablaremos generalmente de la Prevención. El Principio Precautorio (o más bien criterio) siempre debe considerarse en la regulación o reforma de algún tema de Derecho Internacional. Declaración de Rio sobre el medio ambiente y el desarrollo, junio, 1992, Cumbre de N.U. para el medio ambiente y el desarrollo, Río de Janeiro, Principio 15: La falta de información cientifica no debe ser excusa para la inacción en la reducción de actividades nocivas, mostrando el usuario que los usos no tendrán un efecto negativo sobre el recurso. WWF/IUCN (2001) The Status of Natural Resources on the High-Seas, WWF/IUCN, Gland, p. 74. También en Estocolmo sobre Contaminantes Orgánicos Persistentes, entre otros. En el marco de la Declaración de Río, aunque el concepto de precaución esté impreso en un instrumento no vinculante, este forma parte de uno de los muchos principios que dan sustancia a una declaración con alto contenido jurídico en la que se expresan compromisos ambientales voluntariamente adquiridos. Nava, C. (2009) Estudios Ambientales, UNAM, Instituto de Investigaciones Jurídicas, México D.F., pp. 58-60.

102 No hay sanciones en el protocolo de Kioto, sí estándares diferenciados de cumplimiento. Saura, J. (2003) El Cumplimiento del Protocolo de Kioto sobre el Cambio Climático, Publicacions Universitat de Barcelona, Barcelona, p. 51.

103 Ley 19.300 de 9 de marzo de 1994, sobre Bases Generales del Medio ambiente.

104 ... cuando haya peligro de daño grave o irreversible, la falta de certeza científica absoluta no deberá utilizarse como razón para postergar la adopción de medidas eficaces en función de los costos para impedir la degradación del medio ambiente. Reflejado v.g. en el art. 5(7) del Acuerdo de la Organización Mundial del Comercio sobre la Aplicación de Medidas Sanitarias y Fitosanitarias.

105 Decreto promulgatorio 1963, Dic. de 1994, Preámbulo, párr. 9. En los casos anteriores entendemos la posibilidad de confusión entre prevención y precaución. 
seguridad humana incluso a falta de certeza cientifica ${ }^{106}$, debiendo aplicarse ampliamente la idea de precaución, incluso como criterio ${ }^{107}$.

Por otra parte recordamos un principio de derecho internacional medioambiental y fundamento económico internacional directo cual es el derecho soberano de los Estados sobre sus recursos naturales y riquezas, el que debe ejercerse en interés del desarrollo y el bienestar de los habitantes del país ${ }^{108}$, pero bajo la responsabilidad de no causar daño o dañar el medio ambiente de otros Estados o zonas fuera de la jurisdicción ${ }^{109}$, la que seguiría la tendencia de convertirse en ius cogens ${ }^{110}$. Así, si fuese imposible la restitutio in integrum, el Estado podría llegar a pagar indemnización ${ }^{111}$ y por lo tanto comprometer el crédito o la responsabilidad financiera del estado conforme a la Constitución ${ }^{112}$.

En dicho sentido creemos se expresa la Convención de las Naciones Unidas sobre el Derecho del Mar113 (CONVEMAR), la cual establece una obligación legal erga omnes para con el medio marino ${ }^{114}$, debiendo tomarse todas las medidas necesarias para proteger y preservar los ecosistemas raros o vulnerables, así como el hábitat de las especies y otras formas de vida marina amenazadas ${ }^{115}$ como las bentónicas, además de prevenir, reducir y controlar la contaminación proveniente de cualquier fuente, dictando leyes y reglamentos particularmente en el caso de los fondos marinos bajo jurisdicción estatal, los que en ningún caso pueden ser menos

106 Expresado principalmente en la Convención marco N.U. sobre cambio climático, Art. 3 y Convenio de Estocolmo sobre Contaminantes Orgánicos Persistentes, Preámbulo párr. 8 y art. 1.

$107 \quad$ Nava (2009) 61.

108 Declaración sobre la Soberanía Permanente sobre los Recursos Naturales, Resolución AG 1803 (XVII) (1962), que da pie al art. 1.2 de los pactos internacionales de derechos civiles y políticos y de derechos económicos, sociales y culturales de 1966, y Declaración del Derecho al Desarrollo, Resolución 41/128 (1986) de la Asamblea General de Naciones Unidas.

109 Declaración de la Conferencia de las Naciones Unidas sobre el Medio Humano, y en especial el principio 21 (Declaración de Estocolmo) integrada al Convenio de Viena para la protección de la capa de ozono en su preámbulo, párr. 3, lo que la hace obligatoria conforme a la mayoría de la doctrina, y Principio 2 de la Declaración de Río de Janeiro.

110 Velázquez, J.C. (2007) El Estudio de Caso en las Relaciones Jurídicas Internacionales, Modalidades de Aplicación del Derecho Internacional, UNAM, México D.F., p. 451.

111 Aunque hay dudas sobre su posibilidad práctica. Soтo (1996) 202-205.

112 Art. 63 (8), C.P.R.

113 De 1984, con Decreto Promulgatorio 1393, Noviembre de 1997.

114 Czybulka, D. y Bosecke, T. (2006) "Marine Protected Areas in the EEZ in Light of the International and European Community Law- Legal Basis and Aspects of Implementation", en Von Nordheim, H., Boedeker, D., and Krause, J. (Edit.), Progress in Marine Conservation in Europe, Springer, Berlin, p. 29. Existen otros instrumentos que se refieren a las obligaciones ambientales de los Estados sobre el medio marino; v.g. Convención de Cartagena, Convención de París o la Convención Báltica. M'Gonigle, Michael (1990) "Developing sustainability and the emerging norms of international environmental law: The case of Land Based Marine Pollution Control", Annuaire Canadien de Droit International, Vol. 28, Tome 28, p. 194.

115 CONVEMAR, art. 192(1) y 194(5). 
eficaces que las reglas, estándares, prácticas y procedimientos recomendados de carácter internacional ${ }^{116}$. Con la misma intención está erigida la facultad estatal de establecer reservas marinas, creando mediante reglamento un procedimiento de clasificación de especies, debiendo el $\mathrm{Mi}$ nisterio de Medio Ambiente aprobar planes de conservación y gestión de especies, y así adoptar medidas para preservar las especies ${ }^{117}$, entre los que se encuentran los planes de prevención expresados por decreto supremo, aunque estos no podrían ser en principio obligatorios ${ }^{118}$.

Por otro lado, se señalan como exigencias para el mundo desarrollado la necesidad de adoptar medidas sobre aquellas áreas que constituyen bienes comunes de la humanidad, para evitar su deterioro, como es susceptible de ocurrir con el efecto de invernadero, el cambio climático, la degradación de la capa de ozono, de los océanos y de sus recursos naturales y la pérdida del patrimonio natural. Todos ellos patrimonio común de la humanidad ${ }^{119}$.

Chile debiese asegurar que las actividades bajo jurisdicción y control respetan el medio ambiente de otros o de áreas más allá de su control ${ }^{120}$, no permitiendo que usen su territorio para actos contrarios a derecho ${ }^{121}$.

116 CONVEMAR, arts. 194(1) y 208(1) y (3).

117 Ley 19.300 del 1 de marzo de 1994 sobre Bases Generales del Medio ambiente (LBGMA), Arts. 34, 37 y 38 .

118 LBGMA, Artículo 44.- Mediante decreto supremo (...) se establecerán planes de prevención o de descontaminación, cuyo cumplimiento será obligatorio en las zonas calificadas (...).

119 Informe Brundtland. Moyano (1995) 231 y sgtes.

120 Corte Internacional de Justicia (CIJ), Legalidad de la Amenaza o Uso de Armas Nucleares, opinión consultiva, ICJ reports, 1996, párr. 29.

121 CIJ, Caso canal de corfú, ICJ, reports 1949 , p. 22. Si es un hecho peligroso, grave, imputable, aún sin prohibición, el riesgo es el factor fundamental y debe evitarse. Aizendstatd Leistenchneider, Najman (2012) "la responsabilidad de los Estados por actos ilícitos, crímenes internacionales y daños transfronterizos", Anuario Mexicano de derecho internacional, Vol. XII, p. 16.

Aunque no haya sanciones explícitas ni se sepa el daño específico, el daño material ha dejado de considerarse elemento esencial en la responsabilidad y la sola violación del deber de no dańar el medio o de no tomar las medidas adecuadas para evitarlo la causa, exigiéndose las obligaciones basadas en la responsabilidad agravada (con dolo). Basado en CANÇADO TRINDADE, Antonio (2005) «International Law for Humankind: Towards a New Jus Gentium - General Course on Public International Law», en Recueil des Cours de l'Académie de Droit International de la Haye, ch. XV, incluyendo la obligación de cooperación para contrarrestar las infracciones. El actual art. 41 y 48 del proyecto de 2001 de la Comisión de Derecho Internacional (CDI) sobre la lesión producto de una violación de una obligación debida con relación a comunidad internacional en su conjunto, entre las cuales estaría la protección del medio ambiente. Fernández Alcaide, Joaquín (2005): "Orden Público y derecho internacional: desarrollo normativo y déficit institucional”, en Rodríguez Carrión, A. y Pérez, E., Soberanía del Estado y Derecho Internacional Homenaje al Profesor Juan Antonio Carrillo Salcedo, Universidad de Sevilla, Córdoba y Málaga, Sevilla, p. 112 y 115.

Por su parte, la CDI estableció la responsabilidad del ilícito internacional cuando exista imputabilidad y haya incompatibilidad de los actos nacionales con las obligaciones internacionales. Vg. CIJ, Caso del personal diplomático y consular, Fallo 24 de mayo de 1980, CIJ Recueil, 1980. Esto sin la necesidad que el incumplimiento dependa de la intención o del 
Esto creemos se hace reglando la extracción con la ley como medida adecuada, lo cual descartaría la simple extracción del hidrato con parámetros de mercado, protegería los bienes y haría cumplir las obligaciones internacionales.

\subsection{2) Obligaciones sobre derechos humanos, comerciales y la seguridad}

No solo podría haber un daño a la propiedad mundial122. Con la expulsión de $\mathrm{CH}_{4}$ y la posible pérdida de vida asociada se podría estar violando derechos fundamentales dentro de la jurisdicción si se establece que no se tomaron medidas necesarias para asegurar el mejoramiento del medio ambiente ${ }^{123}$, afectando incluso la vida humana ${ }^{124}$.

Sabiendo que la ley chilena permite establecer restricciones específicas al ejercicio de derechos para proteger el medio ambiente ${ }^{125}$, y entendiendo que se puede llegar a la posibilidad de estar ante una clase de operación que pueda comprometer el crédito o la responsabilidad financiera del Estado ${ }^{126}$ (esto sin considerar de ilícita la conducta que traería la reacción o contramedidas, socavando igualmente el crédito del Estado ${ }^{127}$ ), es que aparece nuevamente la ley como necesidad.

En la otra área de interés, el agua, una extracción con beneficio parcial podría llegar a considerarse una violación ya que se ha interpretado la integración del derecho al agua en la norma de derechos humanos ${ }^{128}$,

conocimiento de los agentes del Estado. Vg. CIJ, Caso Estrecho de Corfú Fallo 25 de marzo de 1948, CIJ Recueil, 1948, p. 15 y caso Personal Diplomático y Consular ya que Irán no adoptó las medidas apropiadas. Así son entendidos de manera amplia estos actos, al aceptarse expresiones como aquellos incompatibles con las obligaciones nacionales. Crawford, James (2004), Los articulos de la Comisión de Derecho Internacional sobre la responsabilidad internacional del Estado: introducción, texto y comentarios, Cambridge, Dykinson, Madrid, p. 83. Ver art. 2, artículos de la CDI sobre la responsabilidad internacional del Estado por hechos internacionalmente ilícitos, asamblea general naciones unidas, Doc. A/RES/56/83, 28 enero 2002.

122 Palabras de Soтo (1996) 202-205.

123 Pacto Internacional de los Derechos Económicos, Sociales y culturales, Art. 12, Declaración Universal de los Derechos de los Pueblos, Art. 16. Sepúlveda, C. (1980) El lugar del derecho internacional en el universo jurídico, discurso de recepción como miembro de número a la Academia Mexicana de Jurisprudencia y Legislación, correspondiente a la espańola, México, Porrúa, p. 44.

124 Pacto internacional de derechos civiles y políticos, art. 14.

125 Art. 19 (8), C.P.R. En este artículo se basan las normas sobre emisión de metano para motores en ciertas ciudades (decreto 130, 13-MAR-2002 aprueba reglamento establece normas de emisión de monóxido de carbono (co), hidrocarburos totales (hct), hidrocarburos no metánicos (hcnm), metano (ch4), óxidos de nitrógeno (nox) y material particulado (mp) para motores de buses de locomoción colectiva de la ciudad de Santiago.)

126 Art. 63 (8), C.P.R.

127 Conforme al Art. 22, proyecto de artículos CDI, 2001.

128 La Observación General Num.15 del Comité de Derechos Económicos, Sociales y Culturales de las N.U. estableció que está incluido en el derecho a un nivel de vida adecuado y en 
entendiéndose como un derecho esencial, base de los demás derechos ${ }^{129}$. Sumado a esto, la extracción del hidrato sin aprovechamiento del agua, sería una falta al no adoptarse las medidas necesarias para fomentar una utilización más eficiente de los recursos hídricos ${ }^{130}$.

Recordamos también un tema directamente relacionado al económico-medioambiental, al estar oligopolizada la explotación de gas ${ }^{131}$ y en el caso de existir posibilidades de daño permanente: el desarrollo sosteni$b_{l} e^{132}$. Proyectando la cooperación para un sistema económico internacional favorable y abierto, podría ser un llamado de atención ab initio para las partes de la institución que representa dicho sistema, la Organización Mundial del Comercio ${ }^{133}$ (OMC), entre las cuales está Chile ${ }^{134}$, ya que estos han reconocido como motivo de acuerdo la protección del medio ambiente y el incremento del comercio para los países menos adelantados ${ }^{135}$, haciendo directa referencia a ese concepto y a los instrumentos señalados ${ }^{136}$, mientras que el Párrafo 51 de la Declaración Ministerial

el derecho a la salud, incluida la alimentación, actuando como documento interpretativo del Pacto Internacional de Derechos Económicos, Sociales y Culturales conforme a las competencias del órgano.

129 Doc. A/64/L.63/Rev.1. v.g. SCanlon, John, et. al., (2004) Water is a Human Right?, IUCN Enviromental Law Programme, IUCN Enviromental Policy and Paper No. 51, Gland, disponible en http://data.iucn.org/dbtw-wpd/edocs/EPLP-051.pdf, p. 33 y http://www. un.org/spanish/waterforlifedecade/human_right_to_water.shtml [fecha de visita 2 de diciembre de 2011]. Esta es una tendencia que llegó para quedarse; conocido es el caso de la declaración complementaria de Venezuela, Cuba, Bolivia y Uruguay en 2006, el reconocimiento constitucional de este último al derecho, http://www.worldwatercouncil.org/fileadmin/wwc/Library/Official_Declarations/Declaraci_n_Bolivia__Cuba_Uruguay_y_Venezuela_IVFMA1.pdf, Resolución del Consejo de Derechos Humanos A/HRC/RES/18/1.[2 de diciembre de 2011]. Otras manifestaciones internaciones serían: la aprobación el Consejo de Derechos Humanos de 28 de septiembre de 2011 de una nueva resolución compilatoria de buenas prácticas sobre el derecho al agua potable y a un saneamiento saludable, en la que la Relatora Especial ponía especial énfasis en las soluciones prácticas; o la resolución de Organización Mundial de la Salud (OMS) 64/24, de mayo de 2011, haciendo un llamamiento a los Estados para garantizar que las estrategias de salud nacionales contribuyen al logro de los Objetivos de Desarrollo del Milenio (III, núm.19.).

130 Plan de Implementación de Johanesburgo, Aprobada en la $17^{\text {a }}$ sesión plenaria, celebrada el 4 de septiembre de 2002. Párr. 26 (c).

131 JOGMEC o Conocco-Phillips se repiten en las búsquedas mundiales.

132 Expresado por primera vez en el Informe Brudtland. Contiene en su interior dos conceptos clave: el concepto de necesidades en particular esenciales de los pobres del mundo a la que la prioridad principal debería ser dada; y la idea de las limitaciones impuestas por el Estado de la organización tecnológica y social sobre la capacidad del medio ambiente para satisfacer las necesidades presentes y futuras (...). World Commission on Enviroment and Development (WCED) (1987) Our Common Future, Oxford University Press, Oxford, p. 43. Expresado también en La Declaración de Rio y el Programa 21 de N.U.

133 Chile firmó el General Agreement on Tariffs and Trade (GATT) el 19 de marzo de 1949.

134 Desde el 1 de enero de 1995.

135 Preámbulo GATT. Van den Bossche, Peter (2008), The Law and Policy of the World Trade Organization - Text, Cases and Materials, Cambridge, Cambridge University Press, 2nd ed., p. 85.

136 Preámbulos, Acuerdo de Marrakech y decisión sobre comercio y medio ambiente. 
de Doha ordena al Comité de Comercio y Medio Ambiente, junto con el Comité de Comercio y Desarrollo, a servir de foro con el objeto de contribuir a alcanzar el objetivo de un desarrollo sostenible, finalidad que podría tornarse imposible luego de hacer más vulnerable la biodiversidad bentónica, y a su vez, su posible función en el desarrollo económico y socioeconómico ${ }^{137}$.

Sea por el motivo de la falacia del beneficio general ${ }^{138}$ o de la protección del medio ambiente, pareciera que los miembros de la OMC deben manifestarse general y parcialmente acerca de las repercusiones en la seguridad biológica y los beneficios económicos reales para los Estados en desarrollo, al ir dichas intervenciones contra los inicios de la propia organización, regulándolas detalladamente.

Aun con su dificultad conceptual ${ }^{139}$, es interesante también el concepto de seguridad nacional ${ }^{140}$ y humana ${ }^{141}$. Si bien es cierto que desde lo tradicional no se incluyen en el concepto seguridad nacional temas como las necesidades energéticas, la protección de los recursos como el agua y de la vida a largo plazo, hoy cualquier concepto es funcional ${ }^{142}$ al ser eminentemente construcciones sociales ${ }^{143}$ y por lo tanto estaríamos nuevamente frente a la disyuntiva de expresarnos sobre los objetivos permanentes del Estado (y sus acciones político-jurídicas conyunturales) en el plano económico y ambiental, pudiendo llegar a afectarse con la extracción de los hidratos ${ }^{144}$. Por otro lado, aún más si se confirman los daños, la seguridad humana ${ }^{145}$, extensión lógica de la seguridad gene-

137 V.g. Doc. A/64/66/Add. 2, parr. 3. Recordamos que físicamente los espacios marinos y sus problemas están estrechamente relacionados y han de considerarse en su conjunto, como expresa la CONVEMAR.

138 Vg. Franquet Bernis, José María (2002): ¿Por qué los ricos son más ricos en los países pobres? Falacia o modernidad de la globalización económica, Littera Books, p. 39.

139 Véase IEEE (2011), passim. y Cameron (2000) p. 39 y sgtes.

140 Expresado el término principalmente en el Art. 106 de la C.P.R., relativa al Consejo de Seguridad.

141 Utilizado con seriedad por primera vez en el informe sobre desarrollo humano del programa de naciones unidad para el desarrollo de 1994. Krause (2005) p. 21.

142 Cameron, Iain (2000) National Security and the European Convention on Human Rights, Kluwer Law International, The Hague, p. 40-49. En el mismo sentido parece ir la historia constitucional con la opinión de Raúl Bertelsen Repetto sobre la fiscalización de la seguridad nacional. Tomo X, Comisión Ortúzar, Sesión 319ª, del martes 4 de octubre de 1977.

143 Krause (2005) 20.

144 En el mismo sentido el Informe de 1993 sobre Desarrollo Humano del PNUD: El concepto de seguridad debe pasar desde un énfasis exclusivo en la seguridad nacional a un énfasis mucho mayor en la seguridad de la gente, desde la seguridad por medio de las armas a la seguridad por medio del desarrollo humano, desde la seguridad territorial a la seguridad alimenticia, laboral y medio ambiental.

145 Que ayudaba a catalizar el proceso de seguridad y desarrollo, promoviendo la seguridad del individuo. 
ral $^{146}$, podría estar en desmedro en el ámbito ambiental y/o económico al explotarse indebidamente o no explotarse el recurso en absoluto ${ }^{147}$. Si una extracción es complementada con el efectivo y comprobado secuestro del metano, podrían no existir problemas a este respecto, lo que debe ser reglado.

Resumiendo, habría responsabilidad estatal, o podría haberla, debiendo aplicarse en toda interpretación la creación de una ley conforme al Art. 63, núm. 8 y 10 de la C.P.R. por autorizar operaciones que pueden comprometer el crédito o responsabilidad financiera del Estado y por fijar normas de posterior enajenación (distribución) del bien.

\section{3) Alguna LEGislación COMPARAdA}

La importancia del recurso se ha expresado en la aplicación de legislaciones internas o sus exégetas, regulando la extracción, distribución, pago por derechos y/o protección medioambiental. Pero así como en Chile existe una sucinta política legal marina con el Decreto 475 del Ministerio de Defensa ${ }^{148}$, en otros Estados existen leyes marco a las que deben las primeras ceñirse, respetar y ejecutar, particularmente sus principios básicos como veremos.

\section{1) BRASIL}

Existe una normativa base que abarca todos los recursos marinos. Menciona el desarrollo de la explotación sustentable de los recursos marinos, protección de los ecosistemas, biodiversidad y genética, y adopción del principio precautorio para dichos actos, siempre guardándose el Estado la potestad de regular dicha explotación y exploración por ser el objeto

146 Seguridad humana significa seres libres de graves amenazas a los derechos humanos, la seguridad $o$ vida de las personas. Möller Undurraga, Ma. Francisca (2002) "Chile y la Seguridad Humana La importancia de la red informal”, en Revista de Marina, Vol. 119/868, bimestre May-Jun, 3/2002, pp. 232 y 233.

147 Mediante el daño a la seguridad ambiental y económica, dos de las varias formas de seguridad y conforme a la libertad de necesidades. Recordar que está emparentada con el desarrollo humano, y por lo tanto con el desarrollo económico estatal. Iglesia-Caruncho, Manuel (Coord.), (2007) Avances y Retos de la Cooperación Española. Reflexiones para una Década, Fundación Carolina y Siglo XXI, Madrid, p. 315 y Krause (2005) 23. Esto aun cuando hay manifestaciones que parecen no estar de acuerdo, como la política exterior de Canadá. MöLLER (2002) 238.

148 Establece política nacional de uso del borde costero y crea comisión nacional, del 14 de dic. de 1994. En la ley General de Pesca se señalan aplicaciones de principios como el precautorio, pero determinados a la política pesquera, dejando afuera la investigación biológica. Vg. Arts. 1A, 1B, 1C, 2 y 5, Decreto 430 del ministerio de económica que refunde la ley 18.892 . 
último precisamente el mantener los intereses nacionales conforme la Politica Nacional para os Recursos do Mar ${ }^{149}$. La integración, no en normas parciales sino en una general, de los principios internacionales es patente, además con la integración técnica de una comisión que coordina las acciones de la política nacional, todo esto mediante una ley plurianual ${ }^{150}$ que introduce modelos de gestión participativa de los ministerios, investigación e iniciativa privada, prioriza la conservación y aprovechamiento de los recursos naturales e incentiva la cooperación internacional ${ }^{151}$.

\section{2) COREA DEL SUR}

La ley de energía ${ }^{152}$ es integradora de todas sus formas y actúa como marco respecto de los hidratos al considerar como tal al calor, la electricidad y el combustible ${ }^{153}$, además los entiende como energía nueva y renovable ${ }^{154}$, dando así una categoría arbitraria en base a la necesidad estatal ${ }^{155}$. La ley obliga al gobierno regional y nacional a desarrollar un plan en relación al desarrollo de las energías renovables; de tecnologías reductoras de la polución y reducción de gases efecto invernadero y de tecnologías de energía práctica. Los hidratos estarían incluidos en esas políticas ${ }^{156}$, lo que muestra que consideran a la energía como central en su legislación, dando siempre órdenes desde una ley general sobre su uso e implementación y poder a las regiones para desarrollar sus potencialidades.

\section{3) Estados Unidos de AMÉRICA}

Sin perjuicio del programa de búsqueda y desarrollo previo ${ }^{157}$, la Methane Hydrate Research and Development act of $2000^{158}$, es la ley federal que trata sobre su búsqueda y desarrollo extractivo, además de modificar la Mining and Minerals Policy Act of 1970, integrándola, la que se refiere a la política general del estado sobre los recursos minerales dentro de jurisdicción. En la primera de las normas se involucra directamente a los se-

\footnotetext{
149 Apéndice, Núm. 2, 4, 7, y 8, Decreto Nún. 5377, 23 febrero 2005, adopta la Politica Nacional para os Recursos do Mar-PNRM

VIII Plano Setorial para os recursos do mar.

http://www.mar.mil.br/secirm/p-psrm.html [fecha de visita 3 de enero de 2014].

Energy Act (No. 10911), Korea.

Art. 2, Energy Act.

Partain (2012) 612.

Sabemos que no es renovable.

PARTAIN (2012) 612.

157 Desde 1982 Estados Unidos ha estado investigando la ocurrencia de estos compuestos. U.S. department of energy energy resource potential of methane hydrate an introduction to the science and energy potential of a unique resource, netl, U.S. Department of energy, February 2011 , p. 15 .

Ley Pública Núm. 106-193, aprobada el 2 de mayo de 2000.
} 
cretarios de Estado en cuanto a las designaciones de individuos para llevar a cabo el programa de búsqueda y desarrollo ${ }^{159}$, incluyendo el establecimiento de un panel consultivo mixto de expertos para la búsqueda inicial y el desarrollo ${ }^{160}$, se entregan dineros a la secretaría de energía para ejecutar la norma, junto con la creación de un informe especializado sobre el desarrollo del programa implementado, con la posibilidad de recomendaciones de parte de un órgano especializado ${ }^{161}$. Además se establecen beneficios tributarios en el caso de las extracciones en Alaska, fomentando la producción mediante suspensión de Royalties ${ }^{162}$.

Esta norma es ampliada por la Energy Policy Act of 2005, modificando y extendiendo el programa de búsqueda y desarrollo, mostrando incentivos a la producción ${ }^{163}$, la asistencia y coordinación del secretario de energía ${ }^{164}$, integrando responsabilidades a este sobre el desarrollo de alianzas hasta con industrias ${ }^{165}$. De esta manera vemos un marco claro y específico de búsqueda y extracción, guiado por principios generales y siendo constantemente revisado desde el punto de vista técnico reglamentario en intervención multidisciplinar.

\section{4) JAPÓN}

Se establece un marco básico en la Basic Act on Ocean Policy ${ }^{166}$ para la administración oceánica del estado, armonizando y promoviendo el desarrollo de esos recursos con la conservación del medio ambiente marino, siendo obligación del Estado implementar dichas medidas, incluyendo a los hidratos de metano ${ }^{167}$, según los principios básicos de: (1) Armonización de la explotación con la conservación, (2) la seguridad de los océanos, (3) el avance en el conocimiento marino, y (4) promover el desarrollo sano de las industrias oceánicas por su importancia económica y social $^{168}$. También agrega que los explotadores de las empresas deben dirigir

\footnotetext{
159 Sección 3, methane hydrate research and development act.

160 Letra (C) Methane Hydrate Research and Development act.

161 National Research Council. Véase sección 5 y 6. Methane Hydrate Research and Development act of 2000 (30 USC Sec. 2006).

162 Véase United States Code, Title 42, Chapter 149, Subchapter III, Part A, \$ 15909.

163 Título 3, Subtítulo E, modificación de la Energy Policy Act of 2005.

164 Sección 4, modificación de la Energy Policy Act of 2005

165 Bis.

166 Ley núm. 33 del 27 de julio de 2007.

167 Ponencia Terashima, Hiroshi (2009) Ocean Governance and the Japanese Basic Act on Ocean Policy, The United Nations -Nippon Foundation Fellowship Programme, Inaugural AsiaPacific Alumni Meeting, 14 April 2009. Disponible online http://www.un.org/Depts/los/ nippon/unnff_programme_home/alumni/tokyo_alumni_presents_files/alum_tokyo_terashima.pdf [fecha de visita 3 de enero 2014].

Arts. 2, 3, 4 y 5 Basic Act on Ocean Policy.
} 
su negocio según los principios y cooperar con las medidas del gobierno central, el que debe promover su competitividad ${ }^{169}$.

Pretende la renovación del plan básico de extracción estatal, porque la norma se debe revisar cada cinco años ${ }^{170}$, lo que prueba la existencia e interés legislativo, insistiendo en su contemporización técnica, y de la relevancia que se le da al Estado desde el inicio del proceso comercial , fomentando su directa participación ${ }^{171}$.

\section{5) NUEVA ZELANDA}

La Crown Minerals Act de $2013^{172}$, es la base de la entrega de permisos para la extracción o exploración minera ${ }^{173}$. Podría haber dudas sobre su aplicabilidad al no estar incluidos expresamente los hidratos ${ }^{174}$, pero lo es claramente al entenderse petróleo como cualquier hidrocarburo ocurrido naturalmente (diferente al carbón), sea en estado sólido, liquido o gaseoso ${ }^{175}$, siendo este recurso propiedad de la corona ${ }^{176}$ y existiendo la posibilidad de concederse permisos a cambio de un retorno financiero ${ }^{177}$. También se pregunta si se entregarán por la agencia respectiva permisos por separado para la actividad comercial de los hidratos de gas ${ }^{178}$. En cualquier caso, el dominio de la corona en beneficio de Nueva Zelanda ${ }^{179}$ es innegable respecto de un bien con una necesidad de legislación unitaria y principios claros que ayuden a su extracción, pero que no permitan su monopolización ${ }^{180}$.

169 Arts. 10 y 24 Basic Act on Ocean Policy

170 Según el Art. 25. Japan Times, 28 de febrero de 2013. http://www.japantimes.co.jp/ news/2013/02/28/national/japan-plans-viable-methane-hydrate-technology-by-2018/\#. UVD3pxeQWuI [fecha de visita 21 de marzo del 2013].

171 Incluso existe la JOGMEC, empresa estatal.

172 Que modificó la Ley Principal del 22 de Julio de 1991.

173 Parte 1, Titulo 8, Crown Minerals Act

174 Ver Parte 1, Titulo 2, Crown Minerals Act.

175 Parte 1, título 2, Número 1, Crown Minerals Act. Opinión de Barry Barton expresada al autor, Profesor de la Universidad de Waikato, Nueva Zelandia y A Report on Possible Government Interventions to Promote the Sustainable Development of New Zealand's Ocean Resources, Case study 4: Issues and barriers in the development of a gas hydrate sector, disponible en https:/www.mfe.govt.nz/publications/oceans/government-interventionsocean-resources-may06/index.html

176 Parte 1, Título, Crown Minerals Act

177 The Minister may: (a) Require... the payment of money of the crown: (b) include ... a condition requiring payments to the Crown by the permit holder for (i) the rights given by the permit and this Part; and (ii) any minerals obtained by the permit holder under the permit. Parte 1, Titulo, 34, Crown Minerals Act. http://business.newzealand.com/northamerica/en/invest-in-new-zealand/petroleum-andminerals/case-studies/commercial-potential-for-methane-hydrates/, [al 1 de Abril de 2013]

179 Parte 1, Título 6.

180 A Report on Possible Government Interventions to Promote the Sustainable Development of New Zealand's Ocean Resources, Case study 4: Issues and barriers in the development of 


\section{CONCLUSIONES}

Una solución fácil sería su inclusión manifiesta en la C.P.R. o una ley interpretativa de su naturaleza, debido a que mediante el uso de las prerrogativas estatales puede determinarse una naturaleza incluso arbitraria, todo para su goce estatal como se ve en la legislación comparada (vg. Nueva Zelandia). Pero por su necesidad actual debimos analizar todo escenario. Si los hidratos son sustancias individuales, únicas y diferentes a sus partes por mantener una unicidad bajo condiciones, son propiedad del estado e inconcesibles. Se trataría de otro bien limitado en cantidad, con valor económico y relevancia ecológica, concibiendo el interés público y existiendo una razón de texto por no aplicarse la concesión en yacimientos marinos.

Sin embargo las otras alternativas dan idéntico resultado. En el caso que los compuestos fuesen solo hidrocarburos atrapados, ellos están en la nómina de sustancias exceptuadas de la concesibilidad y ubicadas en aguas marítimas. Por su parte, estimando que lo trascendental al determinar su naturaleza no es el hidrocarburo, la dificultad radicaría en pensar que la extracción y explotación comercial del compuesto es lícita por contener agua mediante el sistema de concesiones marítimas o el aprovechamiento de bien nacional. Lo negamos, porque la extracción de esta agua reducida en cantidad produciría menoscabo al bien común, y el legislador ha estimado que los hidrocarburos líquidos y gaseosos tienen una importancia general en la que los particulares no pueden asegurar y satisfacer directamente el interés público. Donde hay la misma razón, debe existir la misma disposición; la imposibilidad de goce amparándose en tan amplios derechos. Por su parte, las concesiones marítimas nacen y se mantienen como una manera de establecer derechos de uso sobre bienes nacionales, mas no se pronuncia respecto del Ius Fruendi en bienes contenidos en dichos lugares, existiendo únicamente dominio sobre el derecho de uso. Rechazamos la aplicación analógica por ir contra la C.P.R. y la propia institución de la concesión.

Descartada su apropiación, la extracción estatal aparece autorizada y favorecida jurídica (principio de independencia estatal) y económicamente (al ser un estado con necesidades energéticas inmediatas). Si bien es cierto es aceptada por algunos la explotación mediante CEO, existen argumentos contra ese camino, principalmente frente al peligro de existir responsabilidad estatal y no fomentar el mejoramiento estatal ni la competitividad empresarial nacional. Así, debe manifestarse la medida más idónea y necesaria que el ordenamiento presenta para regular los fondos

a gas hydrate sector, disponible en https:/www.mfe.govt.nz/publications/oceans/government-interventions-ocean-resources-may06/index.html, S/P 
marinos, expresando de la mejor forma la voluntad estatal de protección de los intereses económicos permanentes estatales, el cumplimiento de obligaciones, la asunción de la responsabilidad, la protección del crédito y la manifestación de la buena fe internacional: la ley.

En lo prescriptivo, vemos tres necesidades. La primera es que antes de una ley especifica puede ser necesario la declaración de reserva marina de dichas áreas por su importancia biológica, la modificación del código de aguas exceptuando el agua de su régimen y/o proponer el uso preferente de partes del mar territorial -art. 1, IV, núm 5, e) Decreto 475-. Paralelamente, es necesaria una ley marco de la política marina que podría estar basada en el Decreto 475, pero integrando conceptos modernos ya aceptados convencionalmente, como la norma brasileña, mostrando los fines de protección ambiental y económicos en la extracción de toda sustancia y por áreas o recursos. Por su parte la ley regulatoria debería incluir no en orden de importancia: (1) los principios constitucionales y de orden público que se busca proteger con su búsqueda, extracción y distribución, (2) las definiciones básicas, particularmente en orden a cerrar cualquier interpretación contraria a la naturaleza esencial de hidrocarburo del hidrato y evitar así más confusiones, (3) ordenar la investigación a futuro sobre la extracción hecha hasta ahora aisladamente, siguiendo la experiencia de los países con normas avanzadas, con estudios sobre la biota y daños al medio ambiente, para luego (4) establecer los actores permanentes o momentáneos -consultores, buscadores y extractores como en la legislación estadounidense y la intervención de actores políticos regionales como en Corea de Sur-, incluyendo un organismo gerente del gas y el agua, o nuevas atribuciones para uno existente, (5) mediante la orden y la efectiva creación de un reglamento realizado por profesionales del área, mostrar los parámetros técnicos de extracción y transporte para evitar el escape de metano y los requerimientos mínimos para intervenir en la biota específica, enumerada no taxativamente,(6) además de los pagos necesarios para una explotación.

\section{Bibliografía CitAda}

\section{Publicaciones}

- Altrichter, Christian (2011): Diversification of the Energy Matrix in the Metropolitan Región of Santiago de Chile with Focus on Renewable Energies (U. Autónoma de San Luis de Potosí y Cologne Univesity, Tesis Master, p. 29.)

- Anaya, M. \& Martínez, J.J. (2007): Problemática del agua en el mundo, manual sobre sistemas de capacitación y aprovechamiento 
del agua de lluvia para el uso doméstico y consumo humano para América Latina y el Caribe (Centro Internacional de Demostración y Capacitación en Aprovechamiento del Agua de Lluvia- PNUMA).

- Aizendstatd Leistenchneider, Najman (2012): "la responsabilidad de los estados por actos ilícitos, crímines internacionales y daños transfronterizos”, en Anuario Mexicano de derecho internacional, Vol. XII.

- Biastoch, A., et al. (2011): "Rising Arctic Ocean temperatures cause gas hydrate destabilization and ocean acidification", en Geophysical Research Letters, Vol. 38, Num. 8, 16 april, doi:10.1029/2011GL047222, 5 pp.

- Bonafè, Beatrice (2009): The relationship between state and individual responsibility for international crimes (Martinus Nijhoff, Leiden).

- Cameron, Iain (2000): National Security and the European Convention on Human Rights (Kluwer Law International, The Hague).

- Cançado Trindade, Antonio (2005) : «International Law for Humankind: Towards a New Jus Gentium - General Course on Public International Law», en Recueil des Cours de l'Académie de Droit International de la Haye (2005) ch. XV

- Canet, Carles, et al. (2010): "Infiltración y escape de fluidos sedimentarios en el fondo marino: estructuras y procesos de mineralización”, en Revista Sociedad Española de Mineralogía, Macla. 12, septiembre, pp. 04-09.

- Carrol, John (2009): Natural Gas Hydrates: A Guide for Engineers (Elsevier, Oxford).

- Claro, L. (1992): Explicaciones de Derecho Civil Chileno y Comparado (Vol. III, Tomo V, Editorial Jurídica de Chile, Santiago).

- Crawford, James (2004): Los artículos de la Comisión de Derecho Internacional sobre la responsabilidad internacional del estado: introducción texto y comentarios (Cambridge, Dykinson, Madrid).

- Demirbas, Ayhan (2010): Methane Gas Hydrate (Springer, London).

- Czybulka, D. y Bosecke, T. (2006): "Marine Protected Areas in the EEZ in Light of the International and European Community LawLegal Basis and Aspects of Implementation", en Von Nordheim, H., Boedeker, D., and Krause, J. (Edit.), Progress in Marine Conservation in Europe, Springer, Berlin, p. 27- 46.

- Díaz-Naveas J. y Frutos J. (Eds.) (2010): Geología Marina de Chile (Comité oceanográfico Nacional de Chile, Pontificia Universidad Católica de Valparaíso, Servicio Nacional de Geología y Minería, Valparaíso). 
- Drnas de Clément, Z. (2001): "Los principios de Prevención y Precaución en Materia Ambiental en el Sistema Internacional y en el Interamericano", en Jornadas de Derecho Internacional, Secretaría General de la Organización de Estados Americanos, OEA, Washington, pp. 81-92.

- Felber, Christian (2012), La economía del bien común, Barcelona, Planeta.

- Fernández Alcaide, Joaquín (2005): “Orden Público y derecho internacional: desarrollo normativo y déficit institucional", en Rodríguez Carrión, A. y Pérez, E., Soberanía del Estado y Derecho Internacional Homenaje al Profesor Juan Antonio Carrillo Salcedo, Universidad de Sevilla, Córdoba y Málaga, Sevilla.

- Ferrer Fougá, Hernán (1999): Chile y la Oceanomineria: Análisis -Perspectivas (Política y Estrategia) (Secretaría General de la Armada, Valparaíso).

- Franquet Bernis, José María (2002): ¿Por qué los ricos son más ricos en los paises pobres? Falacia o modernidad de la globalización económica (Littera Books)

- Gabito, Jorge y Barrufet, María (2010): Gas Hydrate Research Programs: An International Review (Final Report, US Department of Energy- DOE-).

- Hilgenkamp, K. (2006): Enviromental Health: Ecological Perspectives (Jones and Bartlett, London).

- IEEE (2011): La Evolución del Concepto de Seguridad, Documento Marco 05/2011, Instituto español Estudios Estratégicos, junio 2011, Dirección General de Relaciones Institucionales, Ministerio Defensa español.

- Iglesia-Caruncho, Manuel (Coord.), (2007): Avances y Retos de la Cooperación Española Reflexiones para una Década (Fundación Carolina y siglo XXI, Madrid).

- International Energy Agency (IEA) (2011) Key World Energy Statistics, OECD/IEA, París, disponible en <<http://www.iea.org/ textbase/nppdf/free/2011/key_world_energy_stats.pdf $>>$

- Kenneth, J.P., et al. (2003): Methane Hydrates in Quaternary Climate Change: The Clathrate Gun Hypothesis (AGU Books Board, American Geophysical Union, Washington).

- Krause, Keith (2005): "Seguridad Humana: ¿ha alcanzado su momento?”, en Papeles de cuestiones Internacionales, Icaria, Núm. 90, Verano.

- Landín, S. y Castillo, F. (2007): “Importancia de los hidratos de metano como fuente de energía”, en Conciencia Tecnológica, Instituto Tecnológico de Aguas Calientes, Núm. 033, enero-junio. 
- Longás, JuAn CARlos (2009) “los problemas ambientales”, en Bilbao, Javier, et al. (coord..), Temas de Economia Mundial (Madrid).

- López Casillas, Alberto (2004) "Hidratos de gas", Energías y medio ambiente, Ramos Castellanos, Pedro, Universidad de Salamanca, 2004, p. 51

- Mares, David R. \& Martin, Jeremy M. (2012): "Regional Energy Integration in Latin America: lessons from Chile's experience with natural gas", en Third World Quarterly, Volume 33, Issue 1, pp. 55, 57 o 66.

- May, D. y Monaghan, J. (2004): "Can a Single Bubble Sink a Ship?”, en Journal of Scientific Exploration, Universidad de Monach, Vol. 18, No. 2, pp. 307-312.

- Melo Moreno, Vladimir et al. (2005) Identidades 10, grupo Norma, p. 48.

- Milkov, A.V. (2004): "Global estimates of hydrate-bound gas in marine sediments: how much is really out there?", en Earth-Science Reviews, Núm. 66, pp. 183-197.

- Möller Undurraga, Ma. Francisca (2002): "Chile y la Seguridad Humana La importancia de la red informal", en Revista de Marina, Vol. 119/868, bimestre May-Jun, 3/2002.

- Moyano Bonilla, César (1995) "Derecho a un Medio ambiente Sano", en Boletín Mexicano de Derecho Comparado, Serie Año XXVIII, Núm. 82, enero-abril.

- M'Gonigle, Michael (1990) "Developing sustainability and the emerging norms of international environmental law: The case of Land Based Marine Pollution Control", en Annuaire Canadien de Droit International, Vol. 28, Tome 28.

- Nava, C. (2009) Estudios Ambientales (UNAM, Instituto de Investigaciones Jurídicas, México D.F.).

- Navarrete, A. (1991) "Régimen Jurídico de las Concesiones Marítimas”, en Revista Chilena de Derecho, Vol. 25, No. 4, pp. 953991.

- Oceana (2006) Hábitats en Peligro, propuesta de protección OCEANA (Fundación Diversidad, Madrid) http://oceana.org/sites/ default/files/reports/habitats_in_danger_dec2006_SPA.pdf

- Orrego, F. (1991), "La evolución de la responsabilidad internacional del estado en el derecho internacional a la luz de los nuevos criterios para la protección del medio ambiente", en Sociedad Chilena de Derecho Internacional, Estudios 1991, Santiago.

- Ossa, J.L. (2007), Tratado de Derecho de Minería Tomo I (Cuarta Edición, Editorial Jurídica de Chile, Santiago).

- Parkes, J., et al. (2009), "Culturable Prokariotic diversity of deep, Gas Hydrate Sediments: First Use of a Continuous High- Pressure, 
Anaerobic, Enrichment and Isolation System for Subseafloor Sediments (DeeplsoBUG)", en Society for Applied Microbiology, Enviromental Microbiology, Vol. 11, Issue 12.

- Partain, Roy Andrew (2012), "Korea’s Green Energy Laws and Methane Hydrates", en Journal of Law and Policy Research, June 2012. Vol. 12. No. 2, pp. 591-623.

- Ponting, Clive (1992): Historia Verde del Mundo (Paidós, Barcelona).

- Raven, P., et al. (2011): Enviroment (8 ${ }^{\text {th }}$ Edition, John Wiley and Sons, inc., New York).

- Lopez Casillas, Alberto (2004) "Hidratos de gas", en Energías y medio ambiente, Ramos Castellanos, Pedro, Universidad de Salamanca, 2004.

- Sánchez, V. (Dir.) (2010): Derecho Internacional Público (Huygens, Barcelona, $2^{\text {da }}$ Edición).

- Saura, J. (2003): El Cumplimiento del Protocolo de Kioto sobre el Cambio Climático (Publicacions Universitat de Barcelona, Barcelona)

- Scanlon, John, et al. (2004), Water is a Human Right? (IUCN Enviromental Law Programme, IUCN Enviromental Policy and Paper No. 51, Gland). http://data.iucn.org/dbtw-wpd/edocs/EPLP051.pdf

- Seese, William S. \& Daub, William (2005): Quimica (Octava Edición, México, Pearson, p. 408).

- Sepúlveda, C. (1980): El lugar del derecho internacional en el universo jurídico, discurso de recepción como miembro de número a la Academia Mexicana de Jurisprudencia y Legislación, correspondiente a la española (México, Porrúa).

- Sloan, Dendy, et al. (2011): Natural Gas Hydrates in Flow Assurance (Elsevier, Oxford).

- Smil, Vaclav (2008): Energy in Nature and Society: General Energetics of Complex Systems (Massachusetts Institute of Technology press).

- Soto, M. (1996): "General Principles of International Environmental Law", en ILSA Journal of International and Comparative Law, Vol. 3.

- Tortolero, A. (2000): El Agua y su Historia: México y sus desafíos hacia el Siglo XXI (Siglo XXI Editores).

- UNiCEF and World Health Organization (2012): Progress on drinking water and sanitation 2012 update (WHO-UNICEF, New York).

- United Nations Enviroment Program (2008): UNEP yearbook 2008 (UNEP, Kenya).

- Van den Bossche, Peter (2008), The Law and Policy of the World Trade Organization - Text, Cases and Materials, Cambridge, Cambridge University Press, 2nd ed., p. 85. 
- Vargas, Rocío y Valdés, José Luis (edit.) (2006): Recursos Naturales Estratégicos (UNAM).

- Vera, E. y Díaz-Naveas, J. (2010): "hidratos de gas submarino en el margen chileno", en - Díaz-Naveas J. y Frutos J. (Eds.), Geología Marina de Chile (Comité oceanográfico Nacional de Chile, Pontificia Universidad Católica de Valparaíso, Servicio Nacional de Geología y Minería, Valparaíso).

- Vergara, A. (1992): Principios y Sistema del Derecho Minero: estudio histórico-dogmático (Editorial Jurídica, Santiago).

- Velázquez, J.C. (2007): El Estudio de Caso en las Relaciones Jurídicas Internacionales, Modalidades de Aplicación del Derecho Internacional (UNAM, México D.F.)

- Walker, Sally (2007), Minerals, Lerner Publications, p. 7

- World Commission on Enviroment and Development (WCED) (1987): Our Common Future (Oxford University Press, Oxford).

- WWF/IUCN (2001): The Status of Natural Resources on the HighSeas (WWF/IUCN, Gland).

\section{OTROS RECURSOS}

- http://www.latercera.com/noticia/mundo/2012/06/678-468437-9china-alcanza-un-nuevo-record-de-profundidad-para-su-submarinojiaolong.shtml,

- ht t p://view.koreaherald.com/kh/view. php?ud $=20120710001337 \& \mathrm{cpv}=0$,

- http://www.atimes.com/atimes/southeast_asia/mg15ae01.html

- http://www.jogmec.go.jp/english/index.html

- http://www.fondef.cl

- http://www.forbes.com/sites/quora/2012/07/09/how-many-yearsof-oil-do-we-have-left-to-run-our-industrial-civilization-keeping-inmind-that-oil-is-a-resource-and-has-an-economical-end/

- http://energy.gov/articles/us-and-japan-complete-successful-fieldtrial-methane-hydrate-production-technologies

- http://www.un.org/spanish/waterforlifedecade/human_right_to_ water.shtml

- http://business.newzealand.com

- http://www.japantimes.co.jp

- http://www.senado.cl/prontus_senado/site/artic/20130620/ pags/20130620115217.html 